\title{
Prevalence of Acute Otitis Media in North Sumatera Province, Indonesia
}

\author{
Aditiya Yuda Perkasa Alam Simbolon* \\ Faculty of Medicine, Universitas Sumatera \\ Utara, Medan, Indonesia \\ H. Adam Malik General Hospital, \\ Medan, Indonesia
}

\author{
Devira Zahara \\ Faculty of Medicine, Universitas Sumatera \\ Utara, Medan, Indonesia \\ H. Adam Malik General Hospital, \\ Medan, Indonesia
}

\author{
Askaroellah Aboet \\ Faculty of Medicine, Universitas Sumatera \\ Utara, Medan, Indonesia \\ H. Adam Malik General Hospital, \\ Medan, Indonesia
}

\begin{abstract}
Acute Otitis Media (AOM) is the second most prevalent disease in children after Upper Respiratory Tract Infection (URTI). AOM prevalence varies in different countries, ranging between $2.3-20 \%$. Epidemiological studies of AOM in developing countries are very rare. As of today, no prevalence data of AOM found in North Sumatera. Thus, there needs to be epidemiological data to establish prevention strategy and treatment based on population profile. The objective of this study is to acquire prevalence data and patient profiles of AOM in North Sumatera. This is a descriptive study with a cross-sectional design. The study population is all the people living in North Sumatera Province selected through Simple Random Sampling in several chosen sub-districts. The inclusion criteria of this study are the total population who are willing to be the subject of this study. AOM patients were found as many as 37 of 1726 subjects. Therefore, the prevalence of AOM is $2.1 \%$. Women comprise more of the group (51.4\%). The most prevalent age group is $0-5$ years old (45.9\%). The most prevalent symptom is otalgia (37.8\%). The prevalence of AOM in North Sumatera is $2.2 \%$. There is a need for better ear care and screening program for early detection of this disease.
\end{abstract}

Keywords: AOM, prevalence, North Sumatera, epidemiological, treatment

Received: 09 May 2018; Accepted: 22 June 2018; Published: 13 July 2018

\section{INTRODUCTION}

$\mathrm{AOM}$ is the second most prevalent disease found in children after URTI. AOM may affect all ages, but most prevalently found in babies and children aging from three months to three years old [1]. Peak incidence is within the 18-20 months old age group. Highest global prevalence is in children aging one to four years old $(60.99 \%)$ and children aging less than one years old (45.28\%). The number of cases of AOM in adult increases as much as
$2.3 \%$ after 75 years of age [2].

AOM prevalence varies in different countries, ranging between 2.3 - 20\%. Various epidemiological studies in the United States show that the prevalence of AOM case in the first two years of life is as much as $17-20 \%$. The annual cost of antibiotic administration to counter AOM in the United States is around USD 3-5 million. The prevalence of AOM in other developed countries is almost the same as that of the US. Epidemiological studies of AOM

\footnotetext{
${ }^{*}$ Correspondence concerning this article should be addressed to Aditiya Yuda Perkasa Alam Simbolon, Faculty of Medicine, Universitas Sumatera Utara, Medan, Indonesia / H. Adam Malik General Hospital, Medan, Indonesia. E-mail: dr.aditiyasimbolon@gmail.com

(c) 2018 The Author(s). Published by KKG Publications. This is an Open Access article distributed under a Creative Commons AttributionNonCommercial-NoDerivatives 4.0 International License.
} 
in developed countries are very rare [3, 4].

In Southeast Asia, Indonesia holds the rank as the fourth country with highest prevalence of ear diseases (4.6\%). The other three countries are Sri Lanka (8.8\%), Myanmar (8.4\%), and India (6.3\%). Although not the highest, but $4.6 \%$ prevalnece is considered immense to cause social problem within the community - for instance, it affects communication. According to the survey result of seven provinces in Indonesia, AOM is the leading cause of morbidity of the middle ear [5, 6].

There aren't any official national data reporting AOM prevalence. According to the survey on hearing health conducted in 1994-1996 in 7 provinces in Indonesia, it is found that the prevalence of middle ear diseases in Indonesia was as much as $3.9 \%$. Of all the studies from 12 regions in Indonesia, in 2012, AOM is most prevalently found in school-age schildren. Total prevalence of acute otitis media, otitis media with effusion, and chronic suppurative otitis media were $5 / 1000,4 / 1000$, and 27/1000 of children [3].

As of today, no AOM prevalence and patient profile data that is certain enough to represent the patients' profile in North Sumatera. With that fact in mind, we would like to fill the absence.

\section{METHOD}

This is an observational study in descriptive form with cross-sectional design aiming to find the prevalence data of AOM in North Sumatera.

The study population is all the people living in North Sumatera Province who were selected through Simple Random Sampling in several chosen sub-districts, which were Tanjung Morawa Sub-District, Stabat Sub-District, Sibolga Sub-District, and Pandan Sub-District. The inclusion criteria of this study is the total population who are willing to be the subject of this study and the exclusion criteria of this study are those with suppurative otitis media, external otitis, and ear canal atresia.

Subject selection began with stratification within the district/ municipality level. Districts/ municipalities were sorted based on occupant percentage from BPS (Badan Pusat Statistic/ Statistics Indonesia) data in the year 2014. From the data, the districts were divided into two groups, which are (1) those with low percentage of underpriviledged people $(<=12.86 \%)$ and (2) those with high percentage of underpriviledged people $(>12.86 \%)$. From each of the groups, two districts/ municipalities were then chosen through simple random sampling. The chosen ones were Deli Serdang district, Langkat district, Sibolga municipality, and Middle Tapanuli municipality. From each of them, a list of sub-district was formed. One district was then chosen out of the list through simple random sampling.

All of the samples that fulfilled the criteria signed a written informed consent and proceded with anamnesis and physical examination. All of the data collected were then analyzed and presented in frequency distribution table for each of the variable assessed.

\section{RESULTS}

This study is participated by 1726 samples originating from chosen districs/ municipalities in North Sumatera, which comprises of 855 men $(49.5 \%)$ and 871 women (50.5\%).

TABLE 1

FREQUENCY DISTRIBUTION OF THE RESPONDENTS

\begin{tabular}{lll} 
Diagnosis & $n$ & $\%$ \\
\hline Age & & \\
Normal & 1.554 & 90 \\
Otitis Externa & 67 & 3.8 \\
OME & 7 & 0.4 \\
CSOM & 61 & 3.5 \\
AOM & 37 & 2.2 \\
Total & 1.726 & 100 \\
\hline
\end{tabular}

TABLE 2

ACUTE OTITIS MEDIA CHARACTERISTICS

\begin{tabular}{lll} 
Characteristics & $n=37$ & $\%$ \\
\hline Sex & & \\
Men & 18 & 48.6 \\
Women & 19 & 51.4 \\
Age & & \\
$0-5$ years old & 17 & 45.9 \\
$6-11$ years old & 13 & 35.1 \\
$\geq 12$ years old & 7 & 18.9 \\
Chief Complaints & & \\
Hearing Problem & 5 & 13.5 \\
Ear Pain & 14 & 37.8 \\
Ear Discharge & 10 & 27 \\
Sensation of fullness in ear & 8 & 21.6 \\
Stadium & & \\
Hyperemic & 5 & 13.5 \\
Occlusion & 13 & 35.1 \\
Perforation & 10 & 27 \\
Suppuration & 9 & 24.3 \\
\hline
\end{tabular}


The result of ENT (ear, nose, and throat) physical examination shows that 36 participants were suffering from unilateral acute otitis media and 1 participant suffered from bilateral acute otitis media. This shows that the prevalence of acute otitis media from this study is as much as $2.2 \%$.

This study was participated by 37 subjects who fulfilled the inclusion criteria. Of all the subjects, 18 are men $(48.6 \%)$ and 19 are women $(51.4 \%)$ with the most prevalent age group is 0 - 5 years of age.

Ear pain is the most prevalent chief complaint of AOM in 14 participants $(37.8 \%)$, followed by ear discharge in 10 participants $(27 \%)$. Sensation of fullnes in ear was reported by 10 participants $(27 \%)$ and hearing problem was reported by 5 participants $(13.5 \%)$.

Through ENT physical examination, the most prevalent AOM stadium found is occlusion in 13 participants (35.1\%), followed by perforation in 10 participants (27\%) . Suppuration in 9 participants $(24.3 \%)$ each, and hyperemia in 5 participants (13.5\%).

\section{DISCUSSION AND CONCLUSION}

This study was conducted in several chosen regions that represent North Sumatera Province. It was executed from January - March 2016, where as much as 1726 subjects participated. This community based study involved various structures in the society, including goverment administration, community health center, and health cadres as community's health partners.

The prevalence of AOM in North Sumatera found in this study is as much as $2.2 \%$. This number corresponds to previous studies, where AOM prevalence varies between 2.3 - $20 \%$.

Several published studies assessed otitis media data in children from different countries of the world. In another study, Bardach et al reported AOM incidence of 1.171 $36.000 / 100.000$ children, with the highest incidence in the below 5 years old age group in South America and the Carribean. In Asia Pacific countries, otitis media prevalence in school-age children is reported to vary between $3.25 \%$ (Thailand) and $12.23 \%$ (Phillipines) [7].

This study shows that female group comprised of more participants (51.4\%) than that of male (48.6\%).

Similar report published by [8] which shows that male:female ratio of the case is 1:1.2. Olubanjo in another study found that cases with less number of female participants is more dominant. On the other hand, Homoe et al concluded no different distribution between female and male groups. [9] also found no significant difference in AOM prevalnce between different sex groups. As of today, no certain mechanism support the contribution of sex as the risk factor of AOM [3, 8, 9, 10].

This study found that the most prevalent age group is that of $0-5$ years of age (45.9\%), followed by $6-11$ years old age group $(35.1 \%)$, and $\geq 12$ years old group (18.9\%).

Study done by [3], reported that the highest prevalence of otitis media was found in the 2 - 5 years old age group (44.4\%). According to bivarate and multivariate analysis, $<5$ years of age is the most significant risk factor and a dominant factor of acute otitis media. Children aged $<5$ years old has 10 times greater risk of developing acute otitis media compared to those aged 5 years and above [3].

Based on study conducted by [11], the incidence of acute otitis media that was diagnosed within her prospective study was as much of $256 / 1000$ people within a year. The incidence of acute otitis media is higher in 0 - 2 years old age group compared to that of 3 - 5 years old age group [11].

Globally, acute otitis media incidence is estimated to be as much as $11 \%$ anually, exposing 709 cases anually. The peak of icidence falls into 1 - 4 years old age group (61\%) [12].

Babies and children have the highest risk factor to develop acute otitis media, where the peak of prevalence falls between the age of 3 - 36 months old. This is also due to the underdeveloped eustachian tube in children, which will only complete in adult years. Their eustachian tube is shorter and more horizontally positioned, contributing to the easy drainage of nasofaring secretion to the middle ear [3, 13].

This study found that the most prevalent chief complaint is ear pain, which was reported in 14 participants (37.8\%), followed by ear discharge in 10 participants $(27 \%)$. Sensation of fullnes in ear was reported by 10 participants $(27 \%)$ and hearing problem was reported by 5 participants $(13.5 \%)$.

Generally, otitis media present the following symptoms: ear pain (otalgia), fever, hearing decline, and mucopurulent discharge (otorrhea) through tympanic membrane perforation. In babies, where otitis media cases are most prevalently found, symptoms may not be specific: restless, irritable, no appetite, vomiting, fever, and sometimes accompanied by seizure. A study conducted in Finland shows that risk of otitis media increase in children who suffer cough, nose infection, and ear pain. In Nigeria, Akoai et al found otorrhea and otalgia symptoms to be as much as $20 \%$ and $13 \%$ respectively [13].

The most prevalent stadium found in this study is occlusion of the eustachian tube in 13 participants (35.1\%), followed by perforation of the tympanic membrane in 10 
participants (27\%). Suppuration in 9 participants $(24.3 \%)$ each, and hypreremia in 5 participants (13.5\%).

According to study by [11] the most prevalent clinical signs found are tympanic membrane hyperemia (52.8\%) and ear pain (48.4\%). Ear discharge was found $14.4 \%$ of all cases [11].

\section{REFERENCES}

[1] R. H. Albert and N. S. Skolnik, "Treatment and management of acute otitis media," in Essential Infectious Disease Topics for Primary Care. Totowa, NJ: Humana Press, 2008.

[2] L. Monasta, L. Ronfani, F. Marchetti, M. Montico, L. V. Brumatti, A. Bavcar, D. Grasso, C. Barbiero, and G. Tamburlini, "Burden of disease caused by otitis media: Systematic review and global estimates," PloS one, vol. 7, no. 4, pp. 1-12, 2012. doi: https://doi.org/10.1371/journal.pone.0036226

[3] S. Umar, R. D. Restuti, R. Suwento, H. Priyono, and M. Mansyur. (2013) Prevalence and risk factors of acute otitis media in children in East Jakarta municipality. [Online]. Available: https://bit.ly/2VRuOJ0

[4] S. Tong, C. Amand, A. Kieffer, and M. H. Kyaw, "Trends in healthcare utilization and costs associated with acute otitis media in the United States during 2008-2014," BMC Health Services Research, vol. 18, no. 1, pp. 1-10, 2018. doi: https://doi.org/ 10.1186/s12913-018-3139-1

[5] S. S. B. Kardinan, "Characteristics of acute inpatient otitis media patients at Immanuel Hospital Bandung Period january - december 2013," Unpublished thesis, Maranatha Christian University, Bandung, Indonesia, 2014.

[6] Y. Ren, R. K. Sethi, and K. M. Stankovic, "Acute otitis media and associated complications in United States emergency departments," Otology \& neurotology: Official publication of the American Otological Society, American Neurotology Society [and] European Academy of Otology and Neurotology, vol. 39, no. 8, p. 1005, 2018. doi: https://doi.org/10.1097/ MAO.0000000000001929
[7] R. DeAntonio, J. P. Yarzabal, J. P. Cruz, J. E. Schmidt, and J. Kleijnen, "Epidemiology of otitis media in children from developing countries: A systematic review," International Journal of Pediatric Otorhinolaryngology, vol. 85, pp. 65-74, 2016. doi: https://doi.org/10.1016/j.ijporl.2016.03.032

[8] J. A. E. Eziyi, O. A. Oninla, and T. O. Salawu, "Ear infection in primary school children of Southwestern Nigeria," International Journal of Otorhinolaryngology and Head and Neck Surgery, vol. 4, no. 3, pp. 608-612, 2018.

[9] A. H. Chidozie, U. Uchegbu, N. Johnkennedy, U. G., and A. Catherine, "Efeects of gender and seasonal variation on the prevalence of otitis media among young children in Owerri, IMO State Nigeria," International Journal of Recent Scientific Research, vol. 6, no. 6, pp. 4465-4467, 2015.

[10] M. K. Van Dyke, J. Y. Pircon, R. Cohen, S. A. Madhi, A. Rosenblüt, M. M. Parra, and et al., "Etiology of acute otitis media in children less than 5 years of age: A pooled analysis of 10 similarly designed observational studies," The Pediatric Infectious Disease Journal, vol. 36, no. 3, p. 274281, 2017. doi: https://doi.org/10.1097/inf.0000000000001420

[11] J. G. Liese, S. A. Silfverdal, C. Giaquinto, A. Carmona, J. H. Larcombe, J. Garcia-Sicilia, and et al., "Incidence and clinical presentation of acute otitis media in children aged $<6$ years in European medical practices," Epidemiology \& Infection, vol. 142, no. 8, pp. 1778-1788, 2014. doi: https://doi.org/10.1017/s0950268814002556

[12] G. Bowatte, R. Tham, K. J. Allen, D. J. Tan, M. X. Z. Lau, X. Dai, and C. J. Lodge, "Breastfeeding and childhood acute otitis media: A systematic review and meta-analysis," Acta Paediatrica, vol. 104, pp. 85-95, 2015. doi: https://doi.org/10.1111/apa. 13151

[13] G. C. Illechukwu, C. G. A. Ilechukwu, A. C. Ubesie, C. N. Ojinnaka, G. O. Emechebe, and K. Iloh, "Otitis media in children: Review article," Open Journal of Pediatrics, vol. 4, pp. 47-53, 2014. 